\title{
El despojo de las economías campesinas de la Zona Sur de Costa Rica: Memorias de la Unidad Productiva Potrereña 1950-1980
}

Recibido: 12 de agosto 2020 Revisado: 26 de mayo 2021 Aprobado: 3 de junio 2021

Francis Muñoz Calvo Costarricense. Licenciado de la carrera de sociología de la Universidad de Costa Rica. Labora como investigador del Centro de Investigación en Cultura y Desarrollo de la Vicerrectoría de la

UNED (Costa Rica). Actualmente desarrolla una línea de investigación sobre memorias del despojo en la zona sur de Costa

Rica.

Correo electrónico: fmunozc@uned.ac.cr; franmunozcal@gmail.com

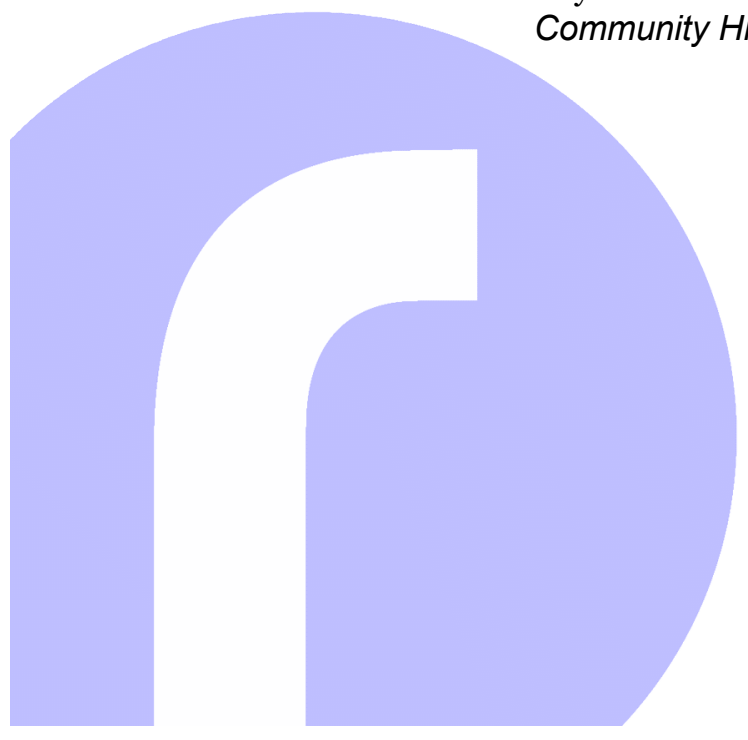

https://revistas.uned.ac.cr/index.php/rupturas cc) (i) (2)
Resumen: Las memorias campesinas de Potrero Grande exponen las repercusiones de los procesos de desarrollo nacional en las localidades de la Zona Sur de Costa Rica. Se analiza el despojo de las economías campesinas de la comunidad de Potrero Grande y su relación con la llegada de las instituciones estatales a mediados del siglo XX. A través de las memorias y otras fuentes históricas, se reconstruirá la historia campesina y las transformaciones socioeconómicas de la etapa desarrollista para la comunidad de Potrero Grande.

Palabras clave: economías campesinas, Estado, Potrero Grande, despojo, historia comunitaria

The dispossession of the peasant economy on the southern side of Costa Rica: Memories from the Unidad Productiva Potrereña 1950-1980

Abstract: The memories of Potrero Grande's peasants expose the repercussions from the national development that took place on the southern side of Costa Rica. The dispossession of the peasant economy of the Potrero Grande's community and its relationship with the arrival of the state institutions during mid 20th century will be analized. The peasant history and the socio-economic transformations from the developmental era, which had an impact on the Potrero Grande community, will be rebuild through memories and other historical sources.

Key words: State, Peasant Economy, Dispossession, Developmentalism, Community History 
1. El desarrollismo fue un proyecto político y económico que institucionalizó la participación de los Estados latinoamericanos dentro de las economías nacionales. Fue a mediados del siglo XX que el proyecto sustitutivo de importaciones y la industrialización de las economías del continente dejó de ser un proceso espontáneo y empezó a ser el objetivo principal de las economías latinoamericanas (Pérez Caldentey 2012).
El inicio de la segunda mitad del siglo XX fue el contexto de profundas transformaciones de la sociedad costarricense, las cuales fueron atravesadas por las reformas desarrollistas que replantearon las relaciones entre el Estado y la economía nacional. La estrategia económica "desarrollista"1 se caracterizó por un conjunto de reformas estructurales y la creación de un robusto cuerpo institucional que le permitió al Estado gestionar y administrar diversas áreas de la vida social del país. El período en cuestión se caracterizó por la "institucionalización del desarrollo" (Edelman 2005), cuya estrategia colocó al Estado como motor de la modernización y diversificación de la economía nacional. En el presente artículo, se desarrollan los alcances de la estrategia desarrollista en la transformación de las economías campesinas de la Zona Sur de Costa Rica. Algunos autores, como Luis Paulino Vargas Solís (2003), plantearon que los pequeños agricultores mantuvieron cierto protagonismo durante la estrategia desarrollista, asimismo, el sociólogo Jorge Rovira Mas (2000) destacó que el nuevo "Estilo de Desarrollo" se encargó de solucionar los problemas agrarios del país. Sin embargo, para el autor Andrés León Araya (2015), los análisis anteriores han limitado sus perspectivas a los procesos que ocurren en el Valle Central, de tal forma que se representa el país como una "entidad unitaria", excluyendo los procesos fuera de las regiones centrales.

Por esta razón, cuando se analiza el período de la estrategia desarrollista, se plantea que el alcance de la intervención estatal fue la misma para todas las regiones del país. Sin embargo, en este trabajo se aborda la transformación de las economías campesinas desde la lente de los procesos comunitarios y su relación con los procesos institucionales del Estado desarrollista. Con ello se pretende, entre otras cosas, trascender el vallecentralismo epistemológico a través de la historia de Potrero Grande, la cual nos remite a una localidad al sur de Costa Rica, en el cantón de Buenos Aires, Puntarenas.

El origen de esta comunidad se debe a las migraciones provenientes de Chiriquí, Panamá, que a su llegada, a inicios del siglo XX, desarrollaron una economía de raíz campesina. Se caracterizaron por el trabajo familiar como medio de producción y reproducción, así como por la autosuficiencia económica y por el desarrollo de una serie de tradiciones de trabajo comunitario que tuvieron lugar en la comunidad. A estas economías con dichas características, se les conocerá con el nombre de Unidades Productivas Potrereñas (UPP).

El concepto de la UPP es medular en este artículo y expresa la historia de la colonización, desarrollo y transformación de una pequeña sociedad que experimentó la integración de un territorio campesino al territorio del proyecto nación. Además, es un concepto que expone las diferentes fases de la historia de Potrero Grande, cuyo origen es el desarrollo de una economía campesina que enfrentó el aumento de la complejidad territorial inducida por los proyectos institucionales del Estado. Por último, la UPP es un constructo sociológico fruto del análisis de distintas fuentes de investigación, cuya finalidad 
académica es abordar las transformaciones socioproductivas de las comunidades campesinas y, por tanto, alberga sesgos y contradicciones del análisis académico y vallecentralino.

En términos metodológicos, este artículo presenta las transformaciones y despojos de la UPP a partir de las narrativas y memorias que fueron recopiladas entre los años 2016 y $2017^{2}$. Se trata de un trabajo principalmente cualitativo y etnográfico que se caracterizó por la recopilación de relatos a partir de diferentes entrevistas y conversaciones enfocadas en la historia de la comunidad de Potrero Grande. Dichas entrevistas produjeron el conjunto de relatos y memorias que representan las fuentes primarias de esta investigación, las cuales fueron analizadas junto con fuentes secundarias provenientes del Archivo Nacional de Costa Rica (ANCR) y una gama amplia de fuentes bibliográficas. Las memorias campesinas de Potrero Grande son el producto de la articulación de tres registros diferentes de la memoria propuestos por el Centro Nacional de Memoria Histórica de Colombia (CNMH 2015): las memorias personales, las memorias colectivas y la memoria histórica ${ }^{3}$. Estas fuentes se triangularon y permitieron corroborar los relatos de la comunidad con otros registros procedentes de las ciencias sociales, dicho ejercicio tuvo el objetivo de nutrir el enfoque etnográfico complementándolo con la "consulta obligatoria de todas las otras fuentes primarias y secundarias" (Fraser 1993, 84). El valor analítico de los relatos de esta investigación surge del análisis de la subjetividad, que es "la investigación de las formas culturales y los procesos mediante los cuales los individuos expresan su sentido de sí mismos en la historia" (Portelli 1989).

A través de memorias ${ }^{4}$ locales y otras fuentes históricas, se expondrá la historia de la comunidad de Potrero Grande y su articulación a los procesos de desarrollo nacional. Primero, nos ubicaremos en la localidad de Potrero Grande, se expondrá el origen de la localidad, así como la cultura campesina originaria que allí se desarrolló y, posteriormente, se reconstruirán los diferentes ciclos de transformación que experimentaron las economías campesinas a partir de la llegada del Estado costarricense. Todo esto desde la perspectiva de las memorias y la historia comunitaria de dicha localidad.

\section{Transformaciones campesinas: el caso de la Unidad Productiva Potrereña 1950-1980}

Como se expuso antes, el objetivo de este artículo es responder cuáles fueron las transformaciones campesinas de Potrero Grande en el contexto desarrollista del país. Específicamente, el planteamiento se concentra en las transformaciones durante el período 1950-1985, el cual se caracteriza por la "institucionalización del desarrollo" (Edelman 2003) en el país y por la llegada sistemática de las instituciones del Estado costarricense al cantón de Buenos Aires. La relación entre ambos procesos es de suma importancia para comprender los cambios de la UPP.

2. Este trabajo expone diferentes resultados de la tesis de investigación Memorias de agricultura, despojos y resistencias en el contexto de las

transformaciones del Estado Desarrollista en el caso de la comunidad de Potrero Grande de Buenos Aires de

Puntarenas 1963-1985 (Muñoz Calvo 2018). En dicha tesis, se lograron constatar los cambios y transformaciones de las economías campesinas potrereñas a través de las narrativas locales e institucionales de la comunidad basadas en la metodología de la memoria.

3. La memoria histórica integra fuentes provenientes de la historia y demás ciencias sociales, se refiere a fuentes académicas de información.

4. Las memorias que se expondrán en este artículo se distinguirán por estar escritas en itálica. El nombre de las personas informantes no se revelará y se expondrán con un pseudónimo. 
5. La crisis generada por la I Guerra Mundial y las decisiones políticas de la administración presidencial de González Flores (1914-1917) originaron un contexto de polarización social que desencadenaron el golpe de Estado comandado por Federico Alberto Tinoco y José Joaquín Tinoco Granados el 27 de enero de 1917, fueron apoyados por la oligarquía, la prensa y la iglesia que sostuvieron su legitimidad en nombre de la "defensa de la democracia"; luego del golpe, los hermanos Tinoco impulsaron unas elecciones llenas de vacíos y en el desarrollo de su régimen impusieron la pena de muerte y la eliminación del voto directo para las elecciones presidenciales imponiendo un régimen dictatorial que se ganó la desaprobación popular paulatinamente (Bonilla Castro 2008).
Potrero Grande se ubica en la Zona Sur de Costa Rica y su origen se dio en un contexto caracterizado por la "soberanía difusa" del Estado costarricense (Royo Aspa 2009) y la falta de presencia institucional en el sur del país. La conformación de la comunidad se vincula al desarrollo de economías campesinas de tipo familiar provenientes de la provincia de Chiriquí, Panamá. Su migración al territorio costarricense se dio por las guerras y la enfermedad que azotaban la provincia de Chiriquí (Amador Matamoros 2008).

Las condiciones sociales al norte de Panamá y la soberanía difusa del Estado costarricense dieron pie a la conformación de pueblos chiricanos en Costa Rica. A su llegada, dichas poblaciones establecieron un modo de vida campesino en un territorio desarticulado de los centros políticos del país, pero con el paso de la Carretera Interamericana, se incentivó la llegada de las instituciones desarrollistas vallecentristas a Potrero Grande. Esto significó la llegada de nuevas visiones y perspectivas productivas a un territorio de raíz campesina y chiricana panameña.

\section{Historia socioproductiva de Potrero Grande}

La historia y origen de Potrero Grande se relaciona con los movimientos migratorios que influyeron la conformación de la Zona Sur. Para Zúñiga et al (2014), los pueblos chiricanos protagonizaron los primeros intentos de colonización campesina de la Zona Sur y, por otra parte, para Antoni Royo (2009), hubo dos corrientes migratorias que dieron forma a esta región: por un lado, los pueblos chiricanos ya mencionados y una corriente proveniente del Valle Central de Costa Rica desde finales del siglo XIX.

Particularmente, el poblado de Potrero Grande se convertiría en el principal núcleo de población chiricana en toda la Zona Sur (Amador 2008). Cuentan los relatos de las personas mayores de la comunidad que, en sus inicios, Potrero Grande se caracterizaba por las abundantes tierras y la propiedad común. A partir del trabajo con relatos orales de la comunidad, fue posible reconstruir la narrativa local de Potrero Grande y el origen de una sociedad de raíz campesina que enfrentaría la llegada de las primeras instituciones estatales y sus funcionarios.

\section{Los primeros: memoria sobre el origen de Potrero Grande}

En sus inicios, el actual distrito de Potrero Grande fue ocupado por los hermanos de apellido Guerra, provenientes de Panamá, quienes ocuparon las sabanas con fines ganaderos en los predios que hoy conforman el centro del distrito (Amador 2008). Por esta razón, los primeros centros de población chiricana ocuparon el lugar conocido como Las Vueltas, sin embargo, en el contexto del conflicto militar de los hermanos Tinoco ${ }^{5}$, los Guerra abandonan la zona y los pobladores de Las Vueltas se trasladan al actual sitio donde se encuentra el centro de Potrero Grande (Chacón 1984). Durante la década de 1920, ese lugar a donde llegaron los chiricanos eran sabanas de pasto natural que habían sido usadas con fines ganaderos. 
Los relatos recuperados por esta investigación describen un Potrero Grande caracterizado por la abundancia de las tierras y por un régimen de propiedad colectiva. Según Celes, una de las mayores de la comunidad potrereña, cuando ella y su familia llegaron a Potrero Grande "no había casas, ni ranchos, no había nada solo montaña" . Según sus relatos, experimentó un momento inicial cuando la comunidad mantenía el ganado de forma colectiva, ella contó que "ahí no se buscaba toro ni nada, sino que era común" (Relato recuperado por el autor, entre los años 2016 y 2017, en la comunidad de Potrero Grande). Sin embargo, a medida que el tiempo pasó, la llegada de nue6. Los relatos representados entre comillas corresponden a la investigación, los cuales constituyen el cuerpo de fuentes primarias de esta investigación recuperadas vos actores complejizaría el paisaje social del incipiente Potrero Grande.

La informante Celes experimentó la llegada de funcionarios y colonizadores provenientes del Valle Central a la comunidad. En su relato, ella describe a esos nuevos actores con el nombre los primeros y su llegada implicó el final de una época caracterizada por las tierras abundantes y de la propiedad colectiva, cambio que fue drástico:

Entonces cuando empezaron a llegar los primeros, comenzaron a robárselo, entonces dice papi hay que hacer cerca y hay que asegurarlo, asegurar ese ganado, porque decía la gente allá pasaron un montón de ganado pa' Volcán por allá y entonces comenzaron la gente a recoger y llegar gente a poner cerca y no había nada de eso, no había cerca ni nada, todo era libre, vieras qué bonito, y entonces llegó un montón de gente y mire como está que no cabe uno pero ni uno (Muñoz Calvo 2018, 125).

Para esos años, Buenos Aires y Potrero Grande experimentaban algunos cambios de tipo político administrativo. En 1914, se decreta Buenos Aires como cabecera del cantón de Osa y Potrero Grande como uno de los distritos; en 1924, aparece el caserío de Las Vueltas como parte del distrito escolar de la zona y, en 1931, llegan el primer policía y profesor a Potrero Grande (Chacón 1984, Amador 2008). Precisamente, la informante Celes cuenta que fue parte de la primera generación escolar y, según ella, "cuando nosotros llegamos no había escuela pero empezaron a trabajar la gente y a llegar más entonces hicieron una escuelita de paja de rancho y la cercaron bien y vieras que bonito" (Muñoz Calvo 2018, 125).

Entonces, los primeros descritos por Celes en su narrativa expresa el conjunto de cambios que configuraron nuevas condiciones territoriales en Potrero Grande a inicios de siglo XX: hablamos de la salida de los hermanos Guerra de Potrero Grande, la llegada de los primeros funcionarios institucionales y el inicio de las colonizaciones provenientes del Valle Central, así como el final de la propiedad común y, por tanto, el primer cercamiento de las tierras en di- 
7. Según Granados y Matarrita (1981), el sistema nativo conserva prácticas como la quema, la roza, el reposo y la rotación. Mientras el sistema tradicional introduce herramientas de producción como la pala, la macana, la ganadería y la voltea de la montaña para despejar árboles del terreno.

8. Tala del bosque primario.

9. La Unidad Productiva Potrereña (UPP). cha comunidad. Pero además la llegada de los primeros funcionarios institucionales empezaría un ciclo de transformaciones de las formas socioproductivas campesinas que repasaremos a continuación.

\section{Vida campesina en Potrero Grande: la Unidad Productiva Potrereña}

Los primeros pobladores de Potrero Grande venían de la región de Chiriquí, Panamá, y a su llegada desarrollaron una economía campesina y familiar. Según las narrativas recuperadas por la investigación, se corroboró que el tipo de agricultura practicada por los primeros habitantes de Potrero Grande combinaba el sistema nativo y tradicional $^{7}$ que, según los autores Granados Chaverri y Matarrita Mena (1981), son sistemas derivados de prácticas propias de los pueblos originarios y de los sistemas introducidos por los colonizadores españoles. En sus inicios, Potrero Grande vivió la quema y la voltea ${ }^{8}$ de los bosques que la conformaban.

Según nos contaba el funcionario Santana, en toda la región "quedaron esas costumbres de quemar maderas preciosas". La cultura productiva de la época consistía en "botar montaña y hacer la finca" como forma de llevar progreso a las zonas periféricas del país (Bozzoli Vargas 1985, 25); en ese contexto, regiones como Buenos Aires fueron foco de ocupación y colonización. Y en esa misma tendencia, se dio el origen de localidades en la zona de Potrero Grande como el caso del pueblo de Jorón, según Natividad "cuando yo me criaba esto de aquí nomás pa' arriba esto era montaña yo voltie montaña de aquí de ahí nomás, hablemos de un kilómetro ahí pa' arriba hasta donde llaman Jorón" (Relato recuperado por el autor, entre los años 2016 y 2017, en la comunidad de Potrero Grande).

De esta forma, Potrero Grande y el resto de Buenos Aires se acampesinaban en medio de tendencias productivas que intensificaban el desbalance ecológico (Carmarck 1994). Algunas de estas eran protagonizadas por formas de vida campesinas basadas en la autosubsistencia y la organización familiar del trabajo, las cuales, a su llegada, practicaron la deforestación sistemática del recurso boscoso para llevar a cabo sus actividades agrícolas y ganaderas. Las economías campesinas de los orígenes de Potrero Grande ${ }^{9}$ se caracterizaban, al igual que las "unidades económicas campesinas" de la teoría, por el trabajo familiar y el abastecimiento de la unidad doméstica de producción (Shanin 1973).

El interés por las transformaciones de las economías campesinas de Potrero Grande permite indagar en el origen y reproducción de prácticas económicas capitalistas en la Zona Sur de Costa Rica. Según el autor Carlos Rodríguez Solera (1993), la economía campesina se caracteriza por el trabajo familiar y la reproducción de la unidad doméstica, por tanto, las economías campesinas se encuentran en los márgenes de la lógica hegemónica de producción y consumo del sistema de producción capitalista. Esto implica que muchas de sus prácticas no son mediadas por el intercambio mercantil, ni tampoco se 
encuentran supeditadas a la explotación y al intercambio de dinero como mediación comercial.

Específicamente, para el caso de la Unidad Productiva Potrereña, se ha registrado un tipo de trabajo comunal basado en formas cooperativas de trabajo en las economías campesinas. Se trata de la tradición de la junta, indiferentemente también llamada peonada y, según la historiadora bonaerense Luz Alba Chacón León: "Las juntas eran reuniones de los vecinos que se congregaban para prestar ayuda a alguno de ellos, para realizar una determinada obra que era de urgente solución" (1986, 130). La junta era una reunión comunal organizada para contribuir en diversas labores de la vida campesina en la que no mediaban relaciones mercantiles y asalariadas.

Las juntas, según Henderson (1958), son una tradición presente en nuestro continente que expresan diversas influencias productivas provenientes de diversas geografías del mundo como España, África y América, como lo indica el autor, "La junta moderna tiene sus raíces en los tres sistemas, pero probablemente sea más española que cualquier cosa. Es imposible definir qué elementos son puramente indios" (166-167). En el caso de las juntas en la Zona Sur de Costa Rica fueron una tradición compartida por pueblos indígenas y campesinos.

Las juntas presentes en Potrero Grande, registradas en diversos relatos de la comunidad, fueron descritas como reuniones comunitarias de trabajo. Su raíz se encuentra en las tradiciones productivas provenientes de Chiriquí, Panamá, y fueron realizadas principalmente para labores agrícolas, en específico en jornadas que demandaban el trabajo de muchas personas. En sus relatos, el señor Beita nos describió que

La palabra jornalero no existía, lo que había, lo que se llamaba era peonada, lo que había eran peonadas, usted tenía se iba a sacar 5 o más hectáreas, entonces nosotros todos nos poníamos de acuerdo, todos los vecinos y usted iba a hacer esa área apearla, a socolarla, a golpearla y todos íbamos con usted y ahí usted, usted se encargaba de la alimentación (Muñoz Calvo 2018, 132).

En la junta no existía el intercambio mercantil como mediación del trabajo, sino que la persona beneficiada por el trabajo de la junta debía garantizar la comida, la chicha y la fiesta. Según Henderson (1958), la junta podía definirse como "fiesta de trabajo comunal" y en ese aspecto coinciden con el carácter festivo con el que fueron ilustradas en las memorias y relatos de Potrero Grande, según cuenta Celes, en las peonadas organizadas por ella se trabajaba y también se celebraba: 
Eso era como decir yo voy donde fulano, pero cuando yo hago viene el dueño de allá, no podían decir fulano va a hacer una junta por que todo mundo venía. Y en la noche eran un bailongo que vieras, hacían una enramada y el zacate estaba así y estaba sequito cuando se iban. Bailaban cumbia, este, cumbia era dar vueltas, pasillo era un baile muy bonito, bueno aquí habían varios pero no se bailaba sacudido como ahora yo no me gusta ver eso, antes se bailaba serenito y todo honradamente porque ahora que va solo andan todos pelados a mí no me gusta eso (Relato recuperado por el autor entre los años 2016 y 2017 en la comunidad de Potrero Grande).

A través de la narrativa de Celes, es posible identificar el aporte femenino dentro de las formas de organización del trabajo en la economía campesina de Potrero Grande. Específicamente, durante las juntas, Celes expresó que "parece que eran más serias las mujeres que andaban por quintales", a diferencia de los relatos narrados por hombres que indicaban que la mujer se dedicaba a labores domésticas de cocina dentro de la Unidad Productiva Potrereña (UPP) y en las juntas. Las voces femeninas en las narrativas recuperadas se encargaron de ilustrar el conjunto de relaciones de género dentro de la UPP.

Si bien los relatos de los hombres tienden a la invisibilización y subordinación de las mujeres exclusivamente a labores domésticas, los relatos de las mujeres expresan que ellas también fueron parte del trabajo agrícola dentro de la UPP. Sin embargo, queda claro que las mujeres en muchos casos fueron excluidas de las labores comerciales y de la administración de los recursos económicos de las unidades productivas. Por ejemplo, la señora Zapata expresó que su trabajo consistía en "hacer lo que papá ordenaba, lo que él decía, la orden eso hacíamos nosotros" (Muñoz Calvo 2018, 137); no obstante, esta subordinación expuesta por la señora Zapata no implicaba que estuviera exenta de efectuar labores agrícolas.

Uno de los aportes más importantes para esta discusión son las memorias sobre la antigua tradición de pilar arroz de forma manual. Antes de la llegada de las piladoras mecánicas, las mujeres cumplían una función muy importante en las piladas de arroz, la señora Celes explicó que el arroz no se pilaba mecánicamente, e inclusive ella particularmente no era igualada por ningún hombre en dicho trabajo: "A mí me echaban gente a ver si me ganaban y no me ganaban, los hombres se ponían pañuelos y comenzaban a sobarse y yo no, yo tenía la mano limpia" (Muñoz Calvo 2018, 138). 
A pesar de que un primer conjunto de relatos invisibilizó la labor de las mujeres en la escena del trabajo agrícola de la UPP, los relatos de Celes y otras mujeres terminan de expresar de mejor forma la diversidad de aportes hechos por ellas. Aun así, es claro que la Unidad Productiva Potrereña se caracterizó por la predominancia del hombre en aspectos esenciales de la economía doméstica, como la comercialización y administración de la unidad productiva. En este caso, labores como las piladas manuales tenían un lugar importante como mecanismos de acceso e inclusión económica para las mujeres, pues dicha labor era remunerada en muchos casos. Sin embargo, en este artículo se plantea que con las transformaciones socio-productivas posteriores, mediadas por la mecanización y modernización introducida en la comunidad por los funcionarios y migrantes vallecentralinos, las mujeres fueron relegadas aún más al ámbito doméstico de la economía de la UPP.

Hasta aquí hemos caracterizado la UPP como una unidad doméstica de economía familiar, cuyo pilar es la familia como eje de producción y reproducción, aspecto que le permite mantenerse al margen de las relaciones capitalistas de producción y que afianza el sustrato social campesino de dicha unidad. Además, la UPP se caracterizó por otros elementos propios del contexto de la Región Brunca como la raíz indígena y chiricana que implicó la permanencia de aspectos del sistema nativo y tradicional de producción (Granados Chaverri y Matarrita Mena 1981).

El sustrato histórico campesino y el contexto histórico de la Región Brunca fueron condiciones que influyeron en el conjunto de transformaciones de la UPP durante el lapso histórico del modelo económico desarrollista a su llegada al cantón de Buenos Aires.

\section{Las transformaciones productivas de la UPP en el período 1930- 1950}

A inicios de 1930, el caserío de Potrero Grande era un pueblo conformado por personas provenientes de Chiriquí, Panamá, en su totalidad. Se trataba de una comunidad de economía campesina y familiar que conservaba muchas de las prácticas heredadas de sus ancestros panameños, las cuales se caracterizaban por la voltea de la montaña, la quema de suelos y el uso de labores de tipo manual para el procesamiento de las cosechas. Sin embargo, durante esta década, en Potrero Grande empieza un paulatino proceso de integración con las dinámicas sociales del Valle Central y del resto de la región que implicaron importantes cambios de sus formas productivas.

El relato de Celes planteó una serie de cambios y transformaciones que sucedieron durante los primeros años del caserío de Potrero Grande. Precisamente, durante la década de 1930, ocurre la llegada de los primeros funcionarios del Estado en la figura del primer policía y del profesor Francisco de Paula Amador (Amador 2008), momento en el que se daba también la instalación de la industria bananera en la zona de Osa y, por tanto, aumenta la demanda de granos básicos. Entonces, con la llegada de los funcionarios a Po- 
10. Término usado por José Luis Amador para referirse a los nuevos migrantes provenientes del Valle Central que llegaban en dicha época a Potrero Grande. trero Grande y las bananeras en Osa, se configuraron nuevas rutas y conexiones económicas en Potrero Grande.

La llegada de actores institucionales a la comunidad y las nuevas actividades comerciales propiciaron un proceso de transformación territorial en Potrero Grande. En dicho proceso, se gestó la apertura de vías de comunicación que permitieron la llegada de nuevos "fuereños"10 a la comunidad y, con ello, la llegada de prácticas económicas tendientes a la intensificación productiva. Uno de estos fuereños fue el señor René Villalobos, quien introdujo la piladora mecánica en la comunidad (Amador 2008).

La introducción de dicho elemento implicó la mecanización de un trabajo que había sido realizado de forma manual y que, además, permitía la integración de las mujeres en las prácticas productivas de la comunidad. No obstante, implicó el debilitamiento de prácticas productivo-comerciales tradicionales y organizadas por el núcleo familiar de la UPP.

Uno de los cambios más sensibles ocurridos en este período fueron las transformaciones relacionadas con la producción arrocera. Una de las prácticas de raíz chiricana más marcadas dentro del ámbito productivo era la producción de arroz, el cual se componía de una serie de formas manuales de trabajo durante la producción, procesamiento y cosecha de dicho producto. En el contexto de reconfiguración territorial que se vivió con la llegada de los primeros, algunas prácticas y herramientas productivas fueron cambiando paulatinamente con la introducción de nuevas lógicas y herramientas de los "fuereños".

Por ejemplo, "las manotadas" de arroz que, según testimonio de la señora Celes, era una forma de cosechar el arroz en forma de "rollos", los cuales se hacían con una herramienta llamada cortadera. Conforme los datos de fuentes documentales, la cortadera fue sustituida por una herramienta conocida como "chinga", que también se conoce como hoz. Ella describe brevemente la forma de hacer las manotadas:

Cuando ya se terminaba la cortada de arroz por donde quiera usted veía los montones de arroz, pero lo cortaba uno con cortadera no era como ahora que lo hacen con machina que corta el arroz y lo hacen un poco de arroz hacen una rueda ponen el manteado y lo aporreaban, en ese tiempo no, era pura espiga a puro rollo, lo cortaba uno y lo iba poniendo ahí un rollito ahí y otro rollo, y por donde quiera había rollos. Quedaba juntado hacen unas piñas de puro arroz, quedaban unas piñotas grandes de 
puro arroz (Relato recuperado por el autor, entre los años

2016 y 2017 , en la comunidad de Potrero Grande).

Según cuenta el señor Beita, "los ticos vinieron con la hoz que era un machete gurdo que agarraba uno la mata de arroz y va haciendo el rollo con la espiga y toda, entonces lo va haciendo aporreado y saca el arroz" (Muñoz Calvo 2018, 144). La introducción de la hoz implicó el detrimento de la tradición chiricana de cosechar el arroz en manotadas.

Aquí se sembraba arroz pero «espequeado», metro a metro, y lo cogían a manotada cortando rollo con una «cortadera». Llegó ese muchacho con sus hijos y empezó a sembrar con chinga, que es un machetito cortado y bien afilado. Esto se hace agachado. El estilo de los chiricanos era distinto. Antes la gente no se agachaba. Además, los chiricanos solo trabajaban la montaña, no trabajaban tacotales. Volteaban la montaña, la quemaban, la sembraban y después cosechaban (Amador 2008, 160).

La fuente anterior se refiere al señor Claudio Chinchilla, quien llegó como comerciante en la década de 1940. Por esta razón, se puede establecer que, posterior a 1930, sucedió un proceso de reconfiguración territorial con el arribo de actores sociales que introdujeron nuevas lógicas productivas tendientes a la mecanización y al aumento de la productividad, dando como resultado el deterioro de las formas locales de raíz chiricana. Tanto los procesos locales como la llegada a nivel regional del capitalismo agroindustrial de las bananeras en la región de Osa influyeron en una reestructuración de las relaciones productivas. En este contexto se adapta, intensifica y acelera la producción de granos básicos en Potrero Grande, dando como resultado el deterioro de las prácticas de producción originarias de la comunidad.

Según José Luis Amador Matamoros (2008), el antropólogo estudioso de la historia potrereña, "los fuereños" introdujeron otra visión y experiencia. Con el paso de la Carretera Interamericana hasta Pérez Zeledón en la década de 1950, se estimuló aún más la llegada de un nuevo frente colonizador y, acorde con Robert Carmarck (1994), para ese entonces, el cantón de Buenos Aires "era una comunidad de colonización, agraria y rural" (31); y según los testimonios de la comunidad, Potrero Grande sonaba en toda la región por sus bonanzas económicas.

En ese contexto llegan a Potrero Grande nuevos colonizadores y entrevistamos a uno de ellos: el señor Neto Morales, quien venía a probar suerte en la comunidad. A su llegada, Neto percibió que el negocio de la agricultura en la 
11. La Carretera Interamericana significó una "reconfiguración socioespacial" (Ojeda, 2016) que despojó a los pueblos y localidades de sus medios económicos para ser sustituidos por formas de acumulación de capital concretando un proceso de "acumulación por despojo" (Harvey, 2005). comunidad era rentable: "Tal como cuando yo entre aquí diay, se vendía mucha cantidad de frijoles, pusieron el Consejo Nacional de Producción aquí en Potrero, porque demasiada agricultura salía, maíz, arroz y frijoles" (Relato recuperado por el autor, entre los años 2016 y 2017, en la comunidad de Potrero Grande). El testimonio se refiere a la instalación del Consejo Nacional de Producción (CNP) en Potrero Grande, institución que se constituiría como la primera del proyecto desarrollista con presencia en la localidad.

\section{Estrategia desarrollista y sus formas locales: el caso de Potrero Grande 1950-1981}

Las formas del proceso desarrollista en Buenos Aires fueron protagonizadas por la llegada de múltiples instituciones al cantón y el paso de la Carretera Interamericana. La falta de un camino entre el Valle Central y la Región Brunca era una realidad a mediados del siglo XX; sin embargo, los intereses geoestratégicos del Gobierno de Estados Unidos impulsaron el proyecto de la Carretera Interamericana que atraviesa el país hasta la actualidad (Serrano Rodríguez 1976). Su paso permitiría el control geoestratégico del ejército estadounidense y la posibilidad para la región de vías comerciales con el canal de Panamá, pero también impulsaría la llegada del Estado y la estrategia desarrollista.

La llegada de la carretera y las instituciones propiciaron la configuración socioeconómica de los pueblos de la región. El paso de la Carretera Interamericana alteró el cauce del río Térraba, imposibilitando el trasiego comercial que ocurría a través de sus aguas, pero además su paso por Buenos Aires atravesó los territorios indígenas de Térraba y de Rey Curré, cambiando la geografía cultural de los pueblos originarios de la región ${ }^{11}$. A partir de ese momento, Buenos Aires y la Región Brunca pasaron a ser región de planificación por parte del Estado (Bozzoli Vargas 1984).

Antes de 1950, existían instituciones al amparo de la municipalidad de Buenos Aires tales como la Junta Calificadora de Comercio e Industria, la agencia de correos y otras, pero a partir de ese año cambiaría la presencia del aparato institucional con la conformación del Consejo Nacional de Producción (CNP), la Junta Rural de Crédito, el Ministerio de Agricultura y Ganadería (MAG), la Dirección Nacional de Desarrollo (DINADECO), el Instituto de Tierras y Colonización (ITCO), entre otras (Chacón 1986).

Durante la puesta en marcha del proyecto desarrollista, la presencia del Estado en el cantón de Buenos Aires cambió radicalmente. En el caso del distrito de Potrero Grande, no fue la excepción, pues la incidencia de las instituciones sería notable a partir de 1950 con la operación del CNP en la localidad. Según el trabajo de José Luis Amador (2008), el CNP empezó allí la estrategia comercial de compra de granos: "Eran al parecer pequeñas cantidades, pero según se dice, allí se inició esta entidad del Estado costarricense en la compra de granos" (Amador 2008, 162). 
En Potrero Grande, el paso de la Carretera Interamericana generó la llegada de nuevos colonizadores en busca de tierras. La popularidad de las bonanzas productivas atrajo a colonos de toda la región, como Neto Morales, quien venía de Puerto Cortés y comentó sobre el movimiento económico de esos años:

Las tierras estaban muy descansadas y poca gente ganadera había, me entiende, poca gente ganadera había, entonces todo mundo se mantenía con la agricultura con el arroz, los frijoles y se daba muy buena la cosecha, el chancho, me entiende, hasta la gallina se vendía, me entiende, todo, todo, se vendía y ya cuando vino el consejo entonces ya los comerciantes de granos bajaron, porque ya todo mundo pagaban un poquito mejor y todo mundo le vendía al Consejo (Relato recuperado por el autor, entre los años 2016 y 2017 , en la comunidad de Potrero Grande).

La llegada del CNP y su servicio de comercialización de granos marcaron una nueva época para las formas del Estado en la comunidad. Hasta ese momento, dicha presencia se había limitado a la representación de funciona- ${ }^{12}$. La presencia de estos rios o corresponsales tales como el profesor, el cartero y el policía ${ }^{12}$. Sin em- funcionarios fue bargo, a partir de esta década, las instituciones empezarían a instalarse en la comunidad para ejecutar e intervenir mediante proyectos que materializaban la visión de un proyecto nacional de desarrollo.

conceptualizada a través de la narrativa local de los primeros.

13. A través de dicho concepto, el autor Fernán Enrique Buenos Aires y Potrero Grande experimentaban profundas transformaciones González plantea la existencia sociales relacionadas con la integración de dicho territorio a los proyectos de desarrollo del Estado. El paso de la Carretera Interamericana promovió una explosión demográfica en Buenos Aires, que pasó de tener 11042 habitantes en 1963, a 20104 habitantes en 1973 y 27820 en 1983 (Chacón 1986, 100). Pero además de los cambios sociodemográficos, la fase desarrollista significó una evolución importante de las formas "diferenciadas del Estado en el espacio y el tiempo"13 (González 2009).

de subestructuras de poder que componen lo que entendemos por Estado, la propuesta es asumir el Estado como "algo inmerso en la cultura, en la densa gama de relaciones sociales locales (González González 2009, 197). Para el caso de Potrero Grande, la fase desarrollista Este proceso de transformaciones institucionales se da en un momento en significó un cambio importante que la comunidad experimenta un crecimiento exponencial del comercio agrí- pasó de ser representado por cola. Los relatos indican que en Potrero "el que tenía arroz tenía plata" y, se- funcionarios "corresponsales" a gún las fuentes de la memoria histórica, el arroz servía de moneda de cambio (Amador Matamoros 2008). En dicho contexto, proliferaron los comercios y las piladoras mecánicas que recibían el arroz de las diferentes unidades productivas potrereñas, así lo cuenta el señor Natividad: "aquí habían, ya le voy en la localidad. 
14. Es importante indicar que los procesos de mecanización y salarización en Potrero Grande son procesos que empiezan con anterioridad al proceso de llegada de las instituciones desarrollistas y de la Carretera Interamericana. Sin embargo, durante la fase desarrollista se intensifican.

15. ANCR. Bancos, EXP. 4682 $(1967,3)$. a decir cuántas máquinas, a donde un señor allá abajo, un, dos, tres piladoras y todas estaban aquí a gas pegado" (Muñoz 2018, 147).

Con la apertura de la ruta de comercialización aérea en Potrero Grande, otros productores preferían exportar el grano y venderlo directamente en la zona de Palmar. El señor Neto Morales expresó que en Potrero Grande "la agricultura era muy barata", por lo que prefería sacarla en avión y venderla directamente en Cortés: "Entonces mire aquí a vender a 25 colones el quintal y allá pilado lo pagaban a 72 colones ¿cuánto más no se ganaba uno?" (Muñoz Calvo 2018, 147). La incorporación de elementos como la piladora mecánica y el trasiego en avioneta eran reflejo de la complejización del espectro productivo de la localidad y que había sido incidido por los primeros.

Este conjunto de relaciones se expresaba también en la configuración de nuevos escenarios de la realidad cantonal en la dimensión socioproductivo. Según datos recogidos en el libro de Luz Alba Chacón León (1984), la extensión de los cultivos de arroz y frijoles crecieron exponencialmente entre los años 1955 y 1973, tales datos permiten inducir que la región de Buenos Aires sufrió un fuerte impacto de los eventos regionales, como el establecimiento de la bananera y el paso de la Carretera Interamericana.

Mientras la intensificación y extensión de la producción agrícola crecía considerablemente en el cantón, en Potrero Grande los procesos de transformación socioproductiva se traducían en el debilitamiento y deterioro de las formas de trabajo originarios de la UPP. Tradiciones tales como las manotadas, las piladas de arroz y las juntas empezaban a dar paso a la mecanización y la salarización del trabajo ${ }^{14}$. Al tiempo que instituciones, como el CNP, se instalaron en la comunidad, las juntas como tradición productiva se encontraban severamente debilitadas y avanzaban las relaciones de trabajo asalariadas.

Según cuenta el señor Beita: "Ya cuando el Consejo estaba aquí ya las peonadas no existían, la siembra sí. Pero eso fue anterior, la peonada y todo eso el consejo no existía" (Muñoz Calvo 2018, 150). Según los registros orales de la comunidad, la última peonada fue en el año 1963 (Relato de la señora Serracín), justamente, para esa década, Potrero Grande era el centro de acopio de una "microrregión" campesina que integraba pueblos como La Puna, Copal, Helechales, Jorón, Los Ángeles y otros. Para ese momento, había en la localidad seis establecimientos que ofrecían el servicio de pilado y comercialización de arroz.

A dichas opciones comerciales, se sumó en 1950, la agencia del CNP que instalaba un centro de acopio en tiempos de $\operatorname{cosech}^{15}$ e implementó su estrategia de "estabilización interna de los precios" dispuesta desde su fundación (CNP 1950). Dicha agencia fue recordada en distintos relatos y memorias como la del señor Natividad: "aquí se salía uno del arroz en octubre y de una vez pegaba a la regada de frijoles hasta finales de octubre, hay veces hasta la primera semana de noviembre, en la última semana de diciembre estaba usted arrancando y aporreando frijoles pa venderle al consejo" (Rela- 
to recuperado por el autor, entre los años 2016 y 2017, en la comunidad de Potrero Grande).

Sin embargo, para otros productores, la agencia del CNP no significó una alternativa comercial rentable. Así lo compartió Neto Morales, quien aseguró que, en su caso, "era bueno pilarlo y echarlo a Cortes como estaba esa bananera a todo dar entonces el arroz siempre se vendía" (Relato recuperado por el autor, entre los años 2016 y 2017, en la comunidad de Potrero Grande). En su experiencia, las transacciones de granos con el Consejo implicaban una serie de regulaciones y requisitos que le parecían "más tallados", pues -como explicó él- la recepción de los granos: "era bien seco el arroz, tenían unos medidores aquí para medir la temperatura, así la humedad, era la humedad, a mí me tocó más de una buscar unos manteados porque le hacía falta un poquito de sol" (Muñoz Calvo 2018, 153).

El CNP y su política de fijación comercial significaron un respaldo comercial importante, pero a nivel local trajo consigo nuevas condiciones y exigencias a las economías de la UPP. Su estricto control de calidad a través del sistema de compras indujo a la adaptación de las cosechas a las exigencias de la institución, algo que no en todos los casos era bien visto por productores como Neto Morales, quien prefería buscar otras opciones comerciales, o como el del señor Leandro, quien prefería venderle a su patrón:

Prefería vendérselo al patrón. Porque él no le claveaba a usted, en el Consejo le sacan basura, le sacan humedad, le sacan y le hacen unos rebajos, entonces dije yo la traída no, mejor se lo vendo a patrón y sembraba donde patrón también, él me daba tierra siempre, me la daba quemadita, entonces él mismo lo compraba (Relato recuperado por el autor, entre los años 2016 y 2017, en la comunidad de Potrero Grande).

De esta forma, se tejía la compleja trama de relaciones socioproductivas en Potrero Grande, donde ya existían diferentes puntos de ventas para la producción agrícola y avanzaban exponencialmente las formas de trabajo asalariadas. Así lo expone la historia del señor Leandro, cuyo relato permite trasladarnos a un mundo de trabajo en Potrero Grande caracterizado por la gran hacienda y el patrón. La Hacienda Caracol fue el lugar donde Leandro, desde muy pequeño, trabajó día y noche desde el año 1954:

Yo comencé a trabajar de 13 años y me ganaba 30 centavos, no 30 colones, 30 centavos y fue trepando de 50 centavos a un colón, de un colón a dos colones y así has- 
ta que emparejé el sueldo mínimo que teníamos en ese tiempo, después de que yo salí de esa finca que yo trabajé años de años en una finca de Kervin Web, un negro, jamaicano, uy pero ese patrón era tan bueno que yo no hallaba como salir de ahí, era como un hijo ahí en la finca (Relato recuperado por el autor, entre los años 2016 y 2017, en la comunidad de Potrero Grande).

El relato de Leandro ilustra la existencia de formas de trabajo asalariadas desde su adolescencia, hablamos de la década de 1950, cuando le tocó enfrentar el reto del trabajo en la Hacienda Caracol. En su entrevista, comentó que nunca participó de la tradición de las peonadas y que su oficio se focalizó en la finca de su patrón, a quien consideraba su padre: "saber ganarse un patrón es más que un tata". Tanto los relatos de Leandro y Neto Morales exponen la configuración de relaciones asalariadas a lo interno de las unidades productivas potrereñas.

El avance de las formas de trabajo asalariadas a nivel local refleja las tendencias que ocurrían a escala nacional. El autor Carlos Rodríguez Solera argumenta que, posterior al año 1950, se dio un proceso de debilitamiento de las formas cooperativas de producción y "la reducción acelerada de la producción destinada al autoconsumo" $(1993,33)$. Dicho desplazamiento de la pequeña agricultura campesina también se materializó en el campo de la producción de granos básicos, y así lo constata Jorge León Saénz (2012), quien presenta cifras que ilustran el desplazamiento de las pequeñas fincas arroceras por la gran propiedad:

Si en 1950 el $80 \%$ de la producción de arroz provenía de fincas menores de 50 hectáreas, en 1973 estas fincas solo van a producir el $23 \%$ de la producción total, mientras que el $77 \%$ restantes será producido por fincas mayores a 50 hectáreas, con una importante concentración en las fincas con 200 hectáreas o más (León 2012, 42).

Entonces, el debilitamiento de las maneras tradicionales de trabajo campesino y el avance de las formas asalariadas en Potrero Grande son reflejo de los procesos impulsados como parte de la estrategia de desarrollo. Recordemos que los objetivos de dicha estrategia consistían en la modernización de las explotaciones y la diversificación de la economía (Mora Alfaro 1992), con el fin de resolver los problemas y la dependencia económica con respecto al sistema agroexportador que había caracterizado al país antes de 1950 (Rovi- 
ra 2000). Las implicaciones de estos procesos fueron el despojo y la destrucción de prácticas desarrolladas por las economías campesinas familiares.

\section{Desarrollismo, conflicto y nueva racionalidad productiva en Potrero Grande}

La relación existente entre las transformaciones de la UPP y el Estado plantea la necesidad de conocer los procesos sociales desarrollados en la Zona Sur de Costa Rica y la localidad de Potrero Grande. Por ello, en esta última sección, se expondrán diferentes relatos de funcionarios institucionales que protagonizaron dicho contexto, sus narrativas se unirán a las memorias campesinas que han estado presentes en las secciones anteriores. Los relatos institucionales expondrán la figura del Estado como parte de las relaciones sociales del territorio y como parte intrínseca de la cultura local (Abrams 1988, González González 2009).

A mediados de la década de 1970, se instaló el Banco Nacional en Potrero Grande, el Ministerio de Agricultura y Ganadería (MAG), así como también llegó el Asistente Técnico de Atención Primaria (ATAP) de la Caja Costarricense de Seguro Social (CCSS). La llegada del grueso de instituciones mencionadas hace de este ciclo la etapa de territorialización del Estado más significativa de su historia. Ello se debe no solo a la presencia de dichos entes en sí, sino también al peso que tuvieron sus funciones en la transformación venidera que empezaba a suscitar como fruto de la "multiterritorialidad", que se configuraba en Potrero Grande.

El concepto de multiterritorialidad obedece a los planteamientos del geógrafo Rogerio Haesbaert (2013), para quien el territorio es la dimensión del espacio abordada bajo el enfoque de las relaciones de poder. Su propuesta es comprender el poder como un elemento disperso entre los diferentes grupos de la sociedad y no como una condición exclusiva del Estado, la perspectiva expuesta consiste en mirar el poder como elemento difuso y desigualmente distribuido en la sociedad entre actores sociales que disputan entre procesos de dominación y resistencia. La multiterritorialidad está compuesta de procesos de territorialización y desterritorialización entre grupos con diferentes cuotas de poder para incidir.

16. La saloma es un gesto "vocal gutural" propio de la

cultura campesina panameña y

La historia de Potrero Grande puede ser vista desde el lente de la multiterritorialidad cuando se comprende la relación entre los ciclos de territorialización estatal y el deterioro de las formas tradicionales de la UPP como desterritorialización campesina. Durante las décadas de 1960 y 1970, existía en Potrero Grande un complejo entramado social caracterizado por el conflicto entre la UPP y los funcionarios del Estado. Dicho conflicto expresaba la contradicción entre la cultura originaria de raíces panameñas y la nueva visión institucional proveniente del Valle Central. Las memorias y narrativas describen que, en Potrero Grande, el policía Tobías Sánchez censuró y castigó la salo$\mathrm{ma}^{16}$ :

que es parte de la tradición musical de géneros como la cumbia, la mejorana y el

tamborito. Según Manuel Zárate y Dora Pérez "se oye durante las escenas de trabajo, mientras se ordeña, se conducen ganados, se muele la caña por la madrugada o cuando se regresa, al anochecer, del trabajo cotidiano" $(1999,26)$. 
17. Según referencias encontradas en el Archivo Nacional en la comunidad de Potrero Grande, el jefe de guardia Tobías Sánchez había sido acusado de fraude $y$ estafa en la malversación de fondos dirigidos a la construcción de caminos (ANCR, Gobernación. Exp. 39816).
Yo salomaba, yo tengo años de no salomar porque diay, el tico tiene de ese más, es racista que vino de afuera que ese es el que vino tratando de agarrar a los hombres por que gritaban, salomaban y tenían sus costumbres, su tradición, los amarraban a un palo, los castigaban (Muñoz Calvo 2018, 164).

Recordemos que la saloma era un componente importante de la cultura potrereña que habían traído consigo los y las ascendientes panameñas desde el origen de la comunidad. La saloma es un gesto gutural que se expresa en la cultura de Chiriquí y que era parte de la tradición campesina en Potrero Grande. Las salomas se practicaban en la cotidianidad, pero también eran parte importante de la tradición productiva de las juntas y de las décimas recitadas durante el trabajo agrícola. Según los relatos, la saloma fue reprimida por el policía Tobías Sánchez quien había tenido diferentes conflictos con la comunidad durante la década de $1960^{17}$.

Para ese entonces, la tradición agrícola en Potrero Grande cedía terreno frente al avance de la producción ganadera y la localidad llegó a ser uno de los principales centros de producción ganadera en el sur del país. Con la finalidad de atender la creciente actividad ganadera del distrito, se estableció el MAG en la comunidad, ya que, según expresó el funcionario Santana "Las fincas se fueron especializando en ganado, todavía hay fincas grandes ahí de ganado y quedaron una gran cantidad de gente aferradas a pequeñas parcelas con granos".

Las cifras a escala cantonal ponen en evidencia el paso de la agricultura a la ganadería en el cantón de Buenos Aires. Conforme datos del trabajo hecho por Carlos Granados y José Matarrita (1981), entre los años 1955 y 1973, la ganadería desplazaría a la agricultura como la actividad principal según el uso de suelos.

Cuadro 1. Buenos Aires: Área ocupada en labores agropecuarias 1955-1973

\begin{tabular}{lcccccc}
\hline \multirow{2}{*}{ Actividades } & \multicolumn{2}{c}{1955} & \multicolumn{2}{c}{1963} & \multicolumn{2}{c}{1973} \\
\cline { 2 - 7 } & Has & $\%$ & Has & $\%$ & Has & $\%$ \\
\hline Tierras de labranza & 17.138 & 31.9 & 25.057 & 26.3 & 27.157 & 21.2 \\
Pastos & 13.361 & 24.8 & 20.707 & 21.8 & 50.600 & 39.6 \\
\hline
\end{tabular}

Fuente: Dirección general de estadísticas y censos tomado en Granados y Matarrita (1981, 113) 
El avance ganadero ocurría frente al deterioro de importantes tradiciones agrícolas campesinas como las juntas y, según el libro de José Luis Amador, para ese momento "se hace notoria la influencia del Estado en la definición de los cultivos que debían sembrar los agricultores mediante la intervención de instituciones como el CNP y los bancos estatales" $(2008,185)$.

Por su parte, en el campo agrícola, el MAG motivó el uso de nuevas técnicas y herramientas en la localidad. La asesoría técnica de la institución impulsó el uso de herramientas como la bomba e insumos productivos como herbicidas y fungicidas, con dicho trabajo, se intentaban adaptar las formas locales a las nuevas tendencias agrícolas de la revolución verde. Según los relatos de Natividad:

Vinieron aquí como a enseñar a la gente a sembrar ya con técnica lo que era abonado y toda esa vara, fungicida digamos pa la chasparrea, para la vaquilla que se las come el frijol, todo eso se le aplicaba al frijol y ahí usted tenía que andar después de la siembra con una bomba cada 8 días fumigando (Muñoz Calvo 2018, 167).

Recordemos que después de 1963, con la conformación del Sistema de Extensión Agrícola, desde el MAG se le dio mucho peso a la difusión de las lógicas productivas de la revolución verde con el fin de impulsar una nueva racionalidad productiva en nuestros países y localidades.

Una nueva racionalidad técnico-productiva se difundió entre los Estados centroamericanos, pero en soporte de sus prioridades políticas tradicionales, por lo que el nuevo proceso de "modernización" agrícola mantuvo las relaciones asimétricas de poder en el campo (Aguilar Sánchez, Cerdas Vega y Llaguno Thomas 2012, 20).

De esta forma, el MAG impulsaba la modernización y diversificación productiva concebidas por la estrategia desarrollista. La asesoría técnica del MAG supeditó las formas de producción propias de la localidad de Potrero Grande $\mathrm{y}$, por el contrario, impulsaba la tecnificación a través del uso de herramientas y semillas ${ }^{18}$ que no les eran propias a la comunidad; sin embargo, para productos tradicionales de la localidad, como el arroz, el señor Natividad expresó que "nunca dieron asesoría". El objetivo de la institución era acercar, nivelar y adaptar las formas agrícolas locales a los cánones de una agricultura modernizada.

Sin embargo, para el extensionista del MAG, el funcionario Montero, dicha estrategia tuvo sus limitaciones en Potrero Grande debido a un problema de mentalidad: "la mentalidad no ha sido una mentalidad de desarrollo". La adaptación propuesta por las instituciones era una agricultura de corte empresarial, mecanizada y regida bajo relaciones asalariadas; sin embargo,

18. Instituciones como el CNP y el MAG impulsaron el uso de especies de semillas de arroz tales como el Rex Oro, Blue Bonnet, Nira Colorado, Nira Blanco, Fortuna Blanco, Fortuna Colorado, así como el frijol México 70 (CNP 1971, 29). Dichas semillas remplazaron las especies locales y, actualmente, son parte del acervo de semillas de los y las productoras de la comunidad de Potrero Grande. 
como se ha repasado en este artículo, las economías agrícolas de Potrero Grande se caracterizaron para dicha época por los rasgos propios de la Unidad Productiva Potrereña: una economía campesina, familiar de autosuficiencia alimentaria.

Por esta razón, nos encontramos frente a dos esquemas económicos distantes uno del otro y que, en algunos casos, representaron conflictos entre miembros de la localidad y funcionarios del Estado que llegaron a tomar el contorno de un conflicto de carácter racial entre ticos y chiricanos panameños. Los relatos de funcionarios institucionales del MAG y algunas memorias campesinas pusieron en evidencia la contradicción existente entre la institución y las formas campesinas de la comunidad. Recordemos que, como precedente, se registró el caso del policía Tobías Sánchez, quien había reprimido la saloma como gesto cultural y festivo de la tradición campesina.

Según los relatos del señor Pinzón, la represión contra la cultura chiricana se trataban de "caprichos de los blancos que no querían los panameños en aquellos tiempos". Las situaciones narradas por los informantes en los relatos anteriores se dan en el contexto de soberanía difusa del Estado costarricense en la Zona Sur del país (Royo Aspa 2009). Por tanto, las formas de territorialización del Estado fueron protagonizadas por corresponsales como el policía, el profesor y el cartero, se trata de un escenario en el que las poblaciones de la región no tenían la necesidad de adscribirse a ninguna de las nacionalidades, sin embargo, se dieron las primeras formas de conflicto racial con la llegada de los primeros funcionarios:

Y vinieron otros policías, que si iba a apuntar el niño mío le preguntaban “¿usted es panameño?” No (respondía). Entonces lo que hacía era que solo las mujeres tenían derecho apuntar a los niños sin los apellidos del tata. Yo le decía póngale el apellido mío y me respondía "Vaya sino le voy a mandar para el otro lado" (al otro lado de la frontera) y si no lo encalabozaban (Relato recuperado por el autor, entre los años 2016 y 2017, en la comunidad de Potrero Grande).

Sin embargo, con la formalización de Potrero Grande dentro del territorio nacional y la puesta en marcha del proyecto desarrollista, el escenario de discriminación racial hacia las poblaciones chiricanas de la localidad no cambió. Cuando se entrevistó a los funcionarios del MAG, explicaron que el problema de la comunidad se trataba un tema de "mentalidad" y su gente eran personas "con aspiraciones de calidad de vida o nivel de vida muy bajas". Pero fueron más enfáticos cuando se refirieron a las personas de origen chiricano 
como una "sambumbia" de gente buena y mala: "son mucha gente de aquí que ya está viciada".

La matriz social racista y discriminatoria es un aspecto constitutivo de la sociedad de Buenos Aires y de la conformación del Estado costarricense como proyecto nación en el sur de Costa Rica; el antropólogo Robert Carmarck había advertido que en los orígenes cantonales "las divisiones 'étnicas' proveían marcadores sociales agudos" $(1994,17)$ y las expresiones registradas por esta investigación, como parte del trabajo de los funcionarios del cantón, expresa la continuidad de dicha matriz racista y discriminatoria que perdura en la cultura política de la comunidad de Potrero Grande y así lo expresó el señor Beita:

Pero vienen los racistas que están aquí en juntas directivas y preguntan que por qué los panameños que aquí que allá que esas costumbres, siempre ha habido una contradicción entre gente tica contra esta gente que tiene inclusive panameño, inclusive somos discriminados hay racismo prácticamente por nosotros, pero nosotros no le hacemos caso a eso (Relato recuperado por el autor entre los años 2016 y 2017 en la comunidad de Potrero Grande).

Las narrativas campesinas y los relatos de los funcionarios de la comunidad de Potrero Grande revelan la relación contradictoria de perspectivas y visiones entre los miembros de la UPP y los funcionarios institucionales. La discriminación experimentada por la población de Potrero Grande hacia el origen panameño y su cultura campesina es parte del proceso de territorialización estatal y el despojo de las formas locales, pero es también el reflejo más violento de la contradictoria relación entre la UPP y las formas locales de territorialización del Estado costarricense. Para profundizar y exponer los resultados finales de la investigación, daremos paso a las conclusiones del artículo.

\section{Conclusiones}

A lo largo de este trabajo, se han expuesto elementos históricos sobre el origen, desarrollo y transformaciones de las Unidades Productivas Potrereñas. Los cambios experimentados por las economías campesinas de la localidad han sido analizados en conjunto con el proceso de territorialización del Estado costarricense en la localidad potrereña a través de diferentes memorias. Recordemos que el objetivo principal del artículo ha sido analizar las transformaciones campesinas de la localidad y su relación con los procesos del Estado en la Zona Sur de Costa Rica. 
19. Según Jorge Rovira (2000), la estrategia desarrollista partía de afrontar las limitaciones de la matriz económica del modelo agroexportador $y$, para ello, se hacía indispensable el impulso de la industria local como eje central del modelo sustitutivo de importaciones. En esa misma línea, Luis Paulino Vargas (2003) plantea que la estrategia desarrollista incentivó la modernización y diversificación económica, ciclo durante el cual las economías agrícolas mantuvieron una participación importante del modelo de desarrollo.
Las principales tendencias académicas sobre la fase desarrollista han expuesto los alcances positivos de la estrategia de modernización y diversificación económica del desarrollismo como un solo proceso político para todo el país por igual ${ }^{19}$. Al hacerlo, han desestimado la experiencia de las comunidades y las consecuencias para sus economías locales con base en perspectivas vallecentralinas. Gracias a las memorias de Potrero Grande, se puede concluir que el alcance de la estrategia desarrollista en la zona sur fue el despojo y la destrucción de las formas económicas locales basadas en el trabajo cooperativo y en los saberes propios originados por las migraciones chiricanas.

Las transformaciones suscitadas entre 1950-1980 en Potrero Grande se comprenden bajo la lupa de la "multiterritorialidad" (Haesbaert, 2013). Según las narrativas locales y el conjunto de fuentes secundarias, Potrero Grande fue descrito como un territorio dinámico que experimentó distintos movimientos de territorialización llevados a cabo desde inicios de siglo XX que, en orden de llegada, fueron: los hermanos Guerra, la presencia militar del gobierno de los Tinoco, la llegada de las primeras familias chiricanas, los primeros funcionarios y la llegada de las instituciones desarrollistas a la comunidad.

Si damos el peso que se merecen dichas fuerzas sociales en la transformación de la matriz campesina de Potrero Grande, encontramos que ocurrió en orden de llegada la territorialización campesina chiricana, la territorialización estatal, la territorialización colonizadora del Valle Central y la paulatina desterritorialización de la cultura chiricana. Como consecuencia, se dio el deterioro y destrucción de las formas económicas locales y, por tanto, el despojo de las formas campesinas originarias como las juntas, las salomas, las manotadas, las piladas de arroz manual y el debilitamiento de la participación femenina dentro de la UPP.

La llegada de los primeros descrita en la narrativa de Celes, cuyo significado es el ciclo de colonización y territorialización estatal en la figura del profesor, incorporó nuevas visiones y perspectivas. Como describe José Luis Amador (2008), "los fuereños" traían otra visión que fue incluida en el ciclo productivo con la apertura de la pista de aterrizaje y la llegada de la piladora mecánica al pueblo. Dicho ciclo de territorialización proveniente del Valle Central implicó el deterioro de alternativas productivas locales que eran realizadas manualmente e incorporaban el rol de la mujer dentro de la matriz productiva.

Por otro lado, el paso de la Carretera Interamericana profundizó la territorialización vallecentralina y configuró el territorio de la Zona Sur de Costa Rica con los intereses geoestratégicos norteamericanos. Su paso implicó la destrucción de actividades culturalmente adoptadas por las comunidades indígenas y campesinas de la región como Térraba, Rey Curré y Potrero Grande, donde la actividad de los boteros era de mucha importancia. Si lo analizamos desde la perspectiva de la antropóloga Diana Ojeda (2016), el paso de la Carretera Interamericana puede entenderse como un "proceso violento de re- 
configuración socioespacial" que limitó de las comunidades mencionadas sobre sus medios de sustento.

Según el autor clásico Karl Marx, el capital como medio de acumulación solo es posible a través del despojo de una parte de la sociedad del acceso a la tierra y la propiedad (1971). De esta forma, la sociedad se polariza entre quienes acceden a los medios de producción y quienes fueron desposeídos, pero también señala que, dicho movimiento, "convierte en capital los medios sociales de vida y de producción, mientras de otra parte convierte a los productores directos en obreros asalariados" $(1971,608)$. O sea, que las formas de despojo planteadas por Marx no se limitan solamente a la expropiación de la tierra, sino que abarca medios sociales de vida que facultan el trabajo y lo hacen posible: conocimientos, saberes, agilidades físicas, entre otras.

Basados en Ojeda Ojeda (2016) y en Marx (1971) encontramos que, en la historia de Potrero Grande, los procesos de territorialización estatal configuraron un proceso de despojo de lo común para dar paso a las tendencias públicas del Estado en su versión desarrollista. Este implicó el desplazamiento progresivo de los medios sociales de vida que la comunidad chiricana de la localidad desarrolló durante un período importante, pero que, con la llegada de los primeros, empezaría a debilitarse progresivamente y a ser remplazado por las lógicas propias de la revolución verde y las formas propias que el capitalismo desarrolló en la comunidad.

Las tendencias descritas anteriormente representan las materializaciones del desarrollismo en Potrero Grande y fueron procesos mediados por las instituciones del Estado costarricense. Con su llegada, arriban proyectos y funcionarios encargados de facilitar los procesos de adaptación y nivelación de las formas locales a las tendencias del desarrollo nacional, en un contexto en que la relación entre formas locales e institucionales desencadenó el conflicto y la discriminación racial por parte de los funcionarios de la comunidad.

Las memorias y narrativas rescatadas en la comunidad de Potrero Grande tienen el valor y potencial de exponer otras caras de los procesos de desarrollo asumidos en el país. A pesar de que los objetivos del modelo desarrollista se orientaban a la meta de resolver "los problemas agrarios" de una economía agroexportadora, la idea de la modernización y diversificación de nuestra economía implicaba transformar los tejidos y entornos sociales con características económicas y culturales muy diversas, las cuales no fueron abordadas como parte de las especificidades regionales y mucho menos locales. Esto trajo como consecuencia el despojo de las tradiciones locales y comunitarias.

Por ello, el principal aporte de este trabajo es el de reflexionar el modelo de desarrollo nacional a la luz de los procesos vinculados a las economías locales. La desarticulación existente entre los procesos de escala nacional gestionados desde la escena hegemónica del poder estatal y los procesos ocurridos a nivel local son parte de la lógica desigual del capitalismo, la necesidad de reproducción del sistema de acumulación del capital destruye todas las ló- 
gicas económicas previas que impiden el proceso de su reproducción. A este proceso incesante de acaparamiento y destrucción del capitalismo, el autor David Harvey lo llama "acumulación por desposesión":

Una mirada más atenta de la descripción que hacer Marx de la acumulación originaria revela un rango amplio de procesos. Estos incluyen la mercantilización y privatización de la tierra y la expulsión forzosa de las poblaciones campesinas; la conversión de diversas formas de derechos de propiedad —común, colectiva, estatal, etc.- en derechos de propiedad exclusivos; la supresión en mercancía y la supresión del derecho a los bienes comunes; la transformación de la fuerza de trabajo en mercancía y la supresión de formas de producción y consumo alternativas; los procesos coloniales (Harvey 2004, 113).

Los procesos de territorialización del Estado en la comunidad de Potrero Grande desencadenaron procesos de diferenciación económica con respecto a las lógicas conocidas durante el origen de la comunidad. Como consecuencia, ocurrió el despojo paulatino y progresivo de las formas locales de producción de la UPP, proceso que se dio a través de la implantación de una nueva lógica productiva y el despojo de las formas de trabajo campesinas originarias de la comunidad.

Se concluye que la lógica productiva implantada a las economías campesinas durante la estrategia desarrollista desestimó los saberes, las raíces culturales y la diversidad de formas económicas del país, con ello se debilitó un importante sustrato económico y social que albergaba importantes y valiosas tradiciones productivas, las cuales fueron sustento de una importante base productiva esencial para la autosuficiencia alimentaria del país.

\section{Bibliografía}

Abrams, Philip. 1988. "Sobre la dificultad de estudiar el Estado". Journal of historical sociology 1(1): 58-89.

Aguilar Sánchez, Carlos, Gerardo Cerdas Vega y Julián Llaguno Thomas. 2012. "Transformaciones y continuidades en el capitalismo agrario centroamericano: el caso de Costa Rica”. En Capitalismo, tierra y poder en América Latina (1982-2012) editado por Guillermo Almeyra. Buenos Aires: CLACSO. 
Amador Matamoros, José Luis. 2008. Historia y tradición de Potrero Grande. San José: EUNED.

Bonilla Castro, Alejandro. 2008. Movimientos sociales y represión del Estado en la dictadura de Tinoco 1918-1919. Diálogos 9: 1510-1538. Acceso el 26 de agosto del 2020: https://revistas.ucr.ac.cr/index.php/dialogos/article/view/31250

Bozzolli Vargas, María Eugenia. 1985. "El desarrollo de la región brunca: tendencias y perspectivas". Revista de Ciencias Sociales 2: 23-32.

Carmarck, Robert. 1994. Soplos de Vientos en Buenos Aires. San José: EUCR, 1994.

Centro Nacional de Memoria Histórica - CNMH. 2015. Claves para navegar por la memoria histórica. Bogotá, Colombia. Acceso el 31 de mayo del 2021 desde: http://www.centrodememoriahistorica.gov.co/descargas/informes2015/ cajaHerramientasMaestros/los-caminos-de-la-memoria-historica.pdf

Consejo Nacional de Producción. 1950. Memoria correspondiente al periodo. Del $1^{\circ}$ de octubre 1949 al 30 de setiembre de 1950. San José, Costa Rica. Acceso el 15 de noviembre del 2017 desde: https://www.cnp.go.cr/

Consejo Nacional de Producción. 1977. Memoria Anual 1976-1977. San José, Costa Rica. Acceso el 18 de noviembre del 2017 desde: https://www.cnp.go.cr/

Chacón León, Luz Alba. 1986. Buenos Aires: Cantón de Puntarenas. San José: Imprenta Nacional, 1986.

Chayanov, Aleksandr. 1974. La organización de la unidad económica campesina. Buenos Aires: Nueva Visión, 1974.

Edelman, Marc. 2005. Campesinos contra la globalización. San José: EUCR, 2005.

Fraser, Ronald. 1993. "La historia oral como historia desde abajo". Ayer 12: 79-92.

González González, Fernán Enrique. 2009. “Espacio, conflicto y poder: las dimensiones territoriales de la violencia y la construcción del Estado en Colombia". Sociedad y Economía 17: 185-214.

Granados Chaverri, Carlos Luis y José Matarrita Mena. 1981. Modo de producción y uso del suelo: el caso de Buenos Aires, Puntarenas. Tesis de licenciatura. Universidad de Costa Rica.

Haesbaert, Rogério. 2013. "Del mito de la desterritorialización a la multiterritorialidad". Cultura y representaciones 81: 9-42.

Harvey, David. 2004. 'El 'nuevo' imperialismo: acumulación por desposesión". Socialist Register 40: 99-129. 
Henderson, Robert. 1958. The Savanna of Central Panama: a study in cultural geography. Tesis doctoral. Universidad de Louisiana.

León Araya, Andrés. 2015. Desarrollo geográfico desigual en costa Rica. San José: EUCR, 2015.

León Saénz, Jorge. 2012. Historia Económica de Costa Rica en el siglo XX: La Economía Rural. San José: EUCR, 2012.

Marx, Karl. 1971. El Capital (Tomo I). México D.F: Fondo de Cultura Económica, 1971.

Mora Alfaro, Jorge. 1992. Los Movimientos campesinos en Costa Rica. San José: FLACSO, 1992.

Muñoz Calvo, Francis. 2018. Memorias de agricultura, despojos y resistencias en el contexto de las transformaciones del Estado Desarrollista en el caso de la comunidad de Potrero Grande de Buenos Aires de Puntarenas 1963-1985. Tesis de licenciatura. Universidad de Costa Rica.

Ojeda Ojeda, Diana. 2016. "Los paisajes del despojo. Propuestas para un análisis desde las reconfiguraciones socioespaciales". Revista Colombiana de Antropología 52 ( 2): 19-43. Acceso el 20 de mayo del 2020,

https://www.icanh.gov.co/nuestra_entidad/grupos investigacion/antropo logia_social/publicaciones_seriadas_antropologia/13089

Pérez Caldentey, Esteban, Osvaldo Sunkel y Miguel Torres Olivos. 2012. Raúl Prebisch (1901-1986): Un recorrido por las etapas de su pensamiento sobre el desarrollo económico. Santiago: CEPAL. Acceso el 26 de agosto del 2020: http://repositorio.cepal.org/handle/11362/40062

Pérez, Dora y Manuel Zárate. 1999. La décima y la copla en Panamá. Panamá: Autoridad del canal de Panamá. Acceso el 20 de febrero de 2020: http://bdigital.binal.ac.pa/bdp/tomolll1.pdf

Portelli, Alessandro. 1989. "Historia y memoria: La muerte de Luigi Trastulli". Historia y Fuente Oral 1: 5-32. Acceso en línea el 26 de agosto del 2018, www.jstor.org/stable/27753227?seq=1

Quesada Monge, Rodrigo. 2008. Ideas Económicas en Costa Rica (18502005). San José: EUNED, 2008.

Rodríguez Solera, Carlos. 1993. Tierra de Labriegos: Los campesinos en Costa Rica desde 1950. San José: FLACSO, 1993.

Rovira Mas, Jorge. 2000. Estado y política económica en Costa Rica 19491970. San José: EUCR.

Royo Aspa, Antoni. 2009. Crisis de dependencia en la Zona Sur. Desarrollo agrario y migraciones internas en el cantón de Osa 1973-2000. San José: EUCR, 2009. 
Serrano Rodríguez, Carlos. 1976. Historia de la carretera interamericana. Tesis de licenciatura. Universidad de Costa Rica.

Shanin, Theodor. 1973. Naturaleza y lógica de la economía campesina. Barcelona: Editorial Anagrama, 1973.

Vargas Solís, Luis Paulino. 2003. Modelo Desarrollista y de industrialización sustitutiva. San José: EUCR, 2003.

Zúñiga Muñoz, Xinia, Pablo Sivas Sivas, Luisa Bejarano Montezuma, Javier Montezuma Montezuma, Leonicio Bejarano Rodríguez, Guillermo García Segura, Juan Antonio Gutiérrez Slon. 2014. La lucha por la cedulación del pueblo ngäbe en Costa Rica: alcances y significados político-culturales en la década del noventa. CICDE-UNED, Costa Rica. Acceso en línea el 15 de agosto del 2020 desde: https://cicde.uned.ac.cr/investigaciones/15-8 